\title{
Differences and similarities between late first-language and second-language learning
}

DIANE LILLO-MARTIN

University of Connecticut \& Haskins Laboratories

(Received: January 20, 2018; final revision received: January 20, 2018; accepted: January 20, 2018; first published online 17 April 2018)

The keynote article by Mayberry and Kluender (2017) clearly shows that there are important effects of delayed exposure to a first language (L1), in linguistic comprehension, production, processing, and even in the brain areas that are active for language. This set of findings is of great importance for both theoretical and practical reasons. As Mayberry and Kluender show, one implication of such findings bears on the theory that a critical period for language (CPL) leads to changes in the ways that language develops when accessible exposure is delayed.

As Mayberry and Kluender also argue, there are important differences between delayed L1 acquisition and the learning of a second language (L2) in adulthood. Mayberry and Kluender argue that such differences indicate that the CPL may not apply when it comes to L2 acquisition (L2A).

However, some questions remain for future research. Here I focus on issues concerning the specific aspects of language affected by CPL, and how this relates to the trajectory of acquisition for both late $\mathrm{L} 1$ and $\mathrm{L} 2$ learners.

The research reviewed by Mayberry and Kluender supports the proposal that at least in part the CPL follows from the fact that phonological categories are acquired during the first year of life. If input is not provided during this period, these categories are not (adequately) formed, and cascading effects may be found in other domains of language.

This is plausible and could be (part) of the explanation for effects seen in both late L1 and L2. As for the late L1 learners, it would be helpful for future research to provide more data regarding the trajectory of phonological production and perception (as of now there are limited data from a few studies, as well as some anecdotal impressions about non-native-like signing).

As for L2, the authors use the fact that a limited number of L2 learners (perhaps 4\%) in fact achieve nativelike phonology (or at least, phonetics) as part of the argument against a CPL for L2. However, their analogy to sexual preference leads to the possibility that in fact, the biological 'usual' is for an L2 CPL, but those $4 \%$ have a slightly different biology, just as in the case of same-sex attraction.

Looking at putative CPL effects in morphology/syntax, it might be helpful for future research to look in more detail at potential break-points that are finer-grained. For example, while numerous studies have reported late learners showing difficulties with ASL inflection, there is one study that finds a distinction between two types of morphology. Berk (2003) found that Mei and Cal, whose immersion in ASL began around age 6, showed difficulties in using verb agreement for person (like other late learners), but they did not have difficulties with a similar morphological system used with spatial verbs. Berk's proposed account for this split bears some resemblance to theories of L2A that target purely formal grammatical features as an area for problems, although there are differences between the proposals in specifics. Such a split between person and spatial marking may indicate that future research should consider potential divisions between aspects of morpho-syntax, rather than looking at these components holistically.

We currently have limited evidence about potential domain-internal splits. In the domain of syntax, there are a few studies of word order, which are limited to a focus on $\mathrm{S} / \mathrm{V} / \mathrm{O}$ order in simple sentences. We don't know much else about the details of syntactic knowledge in late L1 learners, in comparison to the L2 literature, where there are many studies that look at acquisition of different areas within syntax, and some results indicating greater L2 difficulties for phenomena at 'interfaces', e.g., syntax/discourse. Another way to approach this would be more detailed comparisons between native L1A and late L1A; a number of L2A studies have noted similarities and differences to (monolingual) L1A, and such comparisons have contributed to theory development. Interestingly, the grammaticality judgment study by Boudreault and Mayberry (2006) did include various sentence types that produced non-uniform effects, with certain types showing much lower scores by late learners, and an overall pattern

Address for correspondence:

University of Connecticut, Department of Linguistics, 365 Fairfield Way, Unit 1145, Storrs, CT 06269-1145, USA

diane.lillo-martin@uconn.edu 
that is strikingly parallel to that of native signers. This hints at differences within the syntactic domain that can be followed up.

It would be worthwhile to see whether parallels such as the possible one between morphological difficulties in late L1A and L2A are also seen in various syntactic domains. If they are, what can be concluded about the nature of CPL?

Possibly, the CPL does hold for both late L1A and $\mathrm{L} 2 \mathrm{~A}$, and potentially there are ways that $\mathrm{L} 2 \mathrm{~A}$ is different from L1A because of the availability of transfer. Possibly, there are certain effects that follow from lack of exposure during the first year(s) (e.g., phonological category formation), and others that follow from late learning (e.g., certain kinds of morphology). Among the possibilities is also the consideration of grammatical versus processing differences - late learners may be particularly affected in linguistic processing, which might lead to poorer performance on linguistic tests even if natural conversation is less affected. This is plausible given the previous indications of processing differences in learners who were not as severely linguistically deprived; anecdotal indications are that such learners use their sign language successfully for everyday conversation, with differences mainly showing up on testing.

These suggestions for further research do not detract from the overall finding that there are serious long-term effects of delayed access to linguistic input. There are crucial implications for the decisions to be made by hearing families who find out their child is deaf. Putting off input in sign language for later because "it can wait" won't do. Language deprivation has lifelong effects.

\section{References}

Berk, S. (2003). Sensitive period effects on the acquisition of language: A study of language development. Unpublished Ph.D. dissertation. Storrs: University of Connecticut.

Boudreault, P., \& Mayberry, R. I. (2006). Grammatical processing in American Sign Language: Age of firstlanguage acquisition effects in relation to syntactic structure. Language and Cognitive Processes, 21(5), 608635. DOI: $10.1080 / 01690960500139363$.

Mayberry, R. I., \& Kluender, R. (2017). Rethinking the critical period for language: New insights into an old question from American Sign Language. Bilingualism: Language and Cognition doi:10.1017/S1366728917000724 